\title{
O tratamento da autoria: Harry Potter e as fan fictions
}

\section{The treatment of the authorship: Harry Potter and the fan fictions}

Jhony A. SKEIKA*

$U E L$

Josiane A. FRANZÓ**

SECAL

Resumo: Este texto procura fazer uma breve reflexão sobre o estabelecimento da figura autoral, como elemento regulador do texto de ficção, e da função do leitor na (re)construção dos sentidos da narrativa, conforme sugeriu Michel Foucault (1992) e Umberto Eco (1994). Especificamente, fez-se um pequeno estudo de caso do fenômeno das Fan Fictions - ficções escritas por fãs - da série Harry Potter, da escritora inglesa J. K. Rowling, procurando destacar como as relações entre obra/ público e obra/autor acontecem no âmbito do mercado editorial.

Palavras-chave: Autor. Leitor. Harry Potter. Fan Fictions.

Abstract: This text aims to make a short reflection about the establishment of the authorial position, as a regulatory element in the fiction text, and of the reader's function in the narrative's meanings construction, according to Michel Foucault (1992) and Umberto Eco (1994). Particularly, it has brought a small case study of the Fan Fictions phenomenon - fictions written by fans - of the series Harry Potter, by the English writer J. K. Rowling, detaching how the relationships between book/public and book/author take effect inside the publishing market.

Keywords: Author. Reader. Harry Potter. Fan Fictions
* Doutorando em Estudos Literários. jhonyskeika@yahoo. com.br

${ }^{* *}$ Doutora em Literatura. josianefranzo@ hotmail.com 
A função do autor e do leitor no texto ficcional

O autor deveria morrer depois de escrever. Para não perturbar o caminho do texto (ECO, 1985, p. 12).

Michel Foucault, notório pensador francês, problematizou a questão da autoria desenvolvendo, coerente à linha pós-estruturalista em que se inseria, importantes considerações sobre o assunto. Na obra $O$ que é um autor? (1992), ele dialoga sobre a descentralização da figura do Autor (com A maiúsculo), aquele que assina a capa da obra e que seria capaz de arquitetar todos os sentidos e intenções do texto.

Nesse estudo, que foi uma comunicação feita em 22 de fevereiro de 1969 na Sociedade Francesa de Filosofia, Foucault apresenta pensamentos ainda em formulação sobre a noção de autor, já que essa "constitui o momento forte da individualização na história das ideias, dos conhecimentos, das literaturas, na história da filosofia também, e na das ciências” (1992, p. 33). A questão da autoria seria um discurso construído historicamente e para entendê-la seria necessário verificar como tal conceito mudou no decorrer dos anos.

Foucault (1992, p. 48) afirma que até o final século XVIII as narrativas ficcionais - contos, tragédias, comédias e epopeias - eram recebidas, postas em circulação e valorizadas sem que se pusesse em questão a autoria de tais textos: o anonimato não constituía nenhum problema, a sua própria antiguidade (verdadeira ou suposta) era suficiente para garantir a sua autenticidade. Por sua vez, os textos científicos, como os estudos das ciências naturais, só eram considerados como portadores do valor de verdade se fossem assinalados pelo nome de um autor.

A partir do século XVIII houve uma inversão nesse tratamento. A produção científica começa a conceber os discursos por si próprios, como verdades estabelecidas pela constante demonstração e experimentação: os fenômenos observados e estudados passam a ter um caráter não particular, fazendo parte de um corpus científico comum aos homens, negando créditos a apenas uma pessoa. Aos pioneiros de tais estudos, cujo reconhecimento lhes era concedido, restou apenas a função de batizar teorias, conjuntos de elementos, etc. (FOUCAULT, 1992, p. 49).

Porém, em relação aos textos que hoje poderíamos chamar de literários ocorreu o inverso. Passou-se a considerar insistentemente a figura do autor na medida em que a obra ficcional começou a ser tratada como um bem cultural, um produto comercializável ou quando os discursos nela contidos tornaram-se transgressores e, por isso, passíveis de punições (FOUCAULT, 1992, p. 47). É nesse contexto, final do século XVIII e início do século XIX, que se instaura um regime de propriedade de textos, promulgam-se regras de direitos autorais e aquilo que era um produto coletivo, oral e de tradição passa ser uma propriedade, escrita e protegida. 
De acordo com Roger Chartier (1998, p. 34), o autor desse período encontra-se "exposto ao perigo da sua obra", pois assumindo a autoria de seus escritos fica suscetível também à punição, o que o obriga a recorrer à proteção de instâncias de poder, entrando em relações de patrocínio, recebendo pensões ou salários para publicar textos com dedicatórias a pessoas poderosas (CHARTIER, 1998, p. 39). Dessa forma, iniciam-se as relações econômicas ao redor da escrita e publicação de obras. Se o escritor não possuísse bens próprios, cargos, postos, etc., ou não pertencesse a uma linhagem burguesa ou aristocrata, via-se obrigado, sob a condição de continuar escrevendo, a se afiliar às relações de clientela.

É nesse cenário que um novo elemento rouba a cena: o leitor. Os avanços da imprensa no século XIX e a difusão da produção literária propiciada pelas relações de patrocínio “criam” um perfil de leitor não antes conhecido, já que até então a leitura era um sinal de nobreza e distinção típicas da aristocracia (HARMUCH; OLIVEIRA, 2010, p. 12).

Trata-se de um momento em especial em que o modo como se compreendia o que era o leitor se modificou, justamente porque o aumento no número de leitores contribuiu para o gradativo desvanecimento da clareza dos critérios de valores. Ao se estabelecer uma nova relação entre quem escrevia e quem lia, os critérios clássicos determinantes do que era ou não boa literatura foram questionados em nome do surgimento de um outro legislador, o leitor. (HARMUCH; OLIVEIRA, 2010, p. 13).

Apesar desse "novo lote” de leitores que surge neste período, não se pode esquecer ou ignorar que já existia um público interessado em leitura, mesmo que da alta classe, o qual já vinha se formando literariamente ao longo dos tempos. Porém, devido a um número maior de pessoas tendo acesso ao que era apenas da elite, os autores - não os que escreviam apenas por profissão, aumentando quantitativamente a produção escrita da época, mas aqueles que se preocupavam com a qualidade do texto literário - passam a querer "educar" seus compradores, até mesmo criticando a popularização da literatura, daquilo que era considerado uma grande arte e, portanto, para poucos.

Nesse período há um grande posicionamento autoral, cuja voz destaca-se claramente dentro e fora da narrativa literária, registrando o resultado do processo, tanto o de criação quanto o de reflexão, do texto de literatura (HARMUCH; OLIVEIRA, 2010, p. 17). Devido a essa nova configuração do escritor e também dos leitores, a produção literária modifica-se, moldando o que mais tarde ficou conhecido como Romantismo.

A proliferação dos textos ficcionais causada pela imprensa periódica - o folhetim e o nascimento do romance - causou certa instabilidade no exercício de criação literária, fazendo autores buscarem nova delimitação 
para o que seria literatura, refletindo dentro das suas próprias obras sobre o processo de criação narrativa, marcando o período com o fim do prescritivismo ${ }^{1}$ de produção escrita e com um "colapso do universal clássico” (LIMA apud HARMUCH; OLIVEIRA, 2010, p. 14).

Contudo, o aumento significativo do número de compradores de livros não significou necessariamente o surgimento de leitores-modelo de literatura. De acordo com Umberto Eco (1994, p. 22), um leitor-modelo não é aquele que quer apenas saber o que acontece com o protagonista ao final da narrativa, mas o que busca também ler as entrelinhas, capaz de identificar e interagir com as estratégias implícitas arquitetadas pelo autormodelo, que por sua vez não é o autor empírico, o escritor do texto, mas um conjunto de mecanismos e escolhas textuais que estruturam a obra de ficção.

Reiterando tal pensamento, Antoine Compagnon (2003, p. 151) afirma que

[...] o autor implícito se dirige ao leitor implícito (ou o narrador ao narratário), lança as bases de seu pacto, define as condições de entrada do leitor real no livro. O leitor implícito é uma construção textual, percebida como uma imposição pelo leitor real; corresponde ao papel atribuído ao leitor real pelas instruções do texto.

A partir do Romantismo o leitor assume um novo e importante papel na construção dos sentidos do texto. Como escreveu Sartre (apud COMPAGNON, 2003, p. 148), “o objeto literário é um estranho pião que só existe em movimento. Para fazê-lo surgir é preciso um ato concreto que se chama leitura e ele só dura enquanto essa leitura pode durar”. Eco (1994, p. 55) cria uma metáfora muito semelhante: “um texto é uma máquina preguiçosa que pede ao leitor para fazer parte de seu trabalho”.

Ambas as imagens criadas se referem à importante tarefa delegada ao leitor de "dar vida” ao texto. O que Foucault e outros pós-estruturalistas como Roland Barthes propõem em relação à descentralização da figura autoral, então, é a partir de tais mudanças no tratamento da obra literária, quando o leitor assume novo e crucial papel na produção dos sentidos do texto.

Esses pensadores defenderam a morte do autor, já que “o sujeito da escrita está sempre a desaparecer” do texto; a relação com a morte "manifesta-se no apagamento dos caracteres individuais do sujeito que escreve (...); ele retira de todos os signos a sua individualidade particular; a marca do escritor não é mais do que a singularidade da sua ausência” (FOUCAULT, 1992, p. 36 - 37).

A partir desse viés, o leitor seria o único responsável pela significação textual, eximindo o autor empírico - ator real - de qualquer interferência nesse processo; a ideia seria deixar de lado as questões autorais e
${ }^{1}$ Regra que ditava a imitação da temática e da forma da escrita clássica. 
biográficas capazes de intervir em qualquer análise da obra, embora toda construção textual sempre seja arquitetada por uma força organizadora, uma entidade não empírica, porém presente na estrutura e funcionamento do texto, nas escolhas lexicais, narratológicas, etc.

O autor implícito, na terminologia de Compagnon (2003, p. 151), o autor-modelo, na de Eco (1994, p. 23), ou ainda nas palavras de Bakhtin (2003, p. 6), o autor criador constitui semelhantemente o que Foucault chamou de função autor. Para Foucault, o nome do autor é simplesmente um elemento de um discurso, "não transita como o nome próprio, do interior de um discurso para o indivíduo real e exterior que o produziu, mas que, de algum modo, bordeja os textos, recortando-os, delimitando-os, tornando-lhes manifesto o seu modo de ser, ou pelo menos caracterizandolhes” (FOUCAULT, 1992, p. 45 - 46). Em outras palavras, a obra cria um autor.

Nessa perspectiva, não é o autor empírico, a pessoa que escreveu o texto, que se dirige ao leitor, mas uma entidade textual, uma voz que "se manifesta como uma estratégia narrativa, um conjunto de instruções que nos são dadas passo a passo e que devemos seguir quando decidimos agir como o leitor-modelo” (ECO, 1994, p. 21).

Não cabe mais àquele que lê buscar as intenções que o escritor teve para com o texto, mas as intenções da própria obra e de seu arquiteto interno, o autor implícito. Mesmo sendo no leitor, e não o autor, o lugar onde a unidade do texto se produz, no seu destino, não na sua origem, “esse leitor não é mais pessoal que o autor recentemente demolido, e ele se identifica também a uma função”. Segundo Barthes, o autor interno do texto é "esse alguém que mantém reunidos, num único campo, todos os traços de que é construída a escrita” (BARTHES apud COMPAGNON, 2003, p. 51).

Dessa forma chega-se a um autor organizador, um orquestrador de inúmeros discursos que estão inseridos em sua obra e não mais um autor enquanto entidade absoluta, externa e anterior, que tenta explicar suas intenções e sustentar os significados de sua escrita. Como na epígrafe deste estudo, o autor externo deve morrer após escrever, caso contrário, ao tentar elucidar seu escopo para com sua obra, pode delimitar ao ponto de até dizer inverdades sobre o vasto campo de interpretação que a sua literatura pode dispor.

\section{Um estudo de caso: Harry Potter e as Fan fictions}

Em 1997 a escritora, até então desconhecida, Joanne Rowling publica um livro intitulado Harry Potter e a Pedra Filosofal (HP and the Philosopher's Stone), o qual apresenta a história de um adolescente chamado Harry Potter, que descobre, no dia do seu décimo primeiro aniversário, que é um bruxo e que possui uma vaga para estudar magia em 
Hogwarts, uma escola para jovens como ele. A narrativa, à primeira vista destinada ao público juvenil, logo se tornou muito famosa em todo o mundo e foi continuada pela autora em mais seis livros², os quais, assim como o primeiro, ganharam adaptações cinematográficas e até 2011 venderam juntos mais de 450 milhões de cópias ${ }^{3}$.

Sobre a série, há inúmeras considerações que podem ser realizadas a respeito da questão da autoria e recepção dos livros. Todavia, para este estudo, delimitou-se abordar somente o fenômeno Fan fiction - narrativas escritas por fãs - a fim de investigar sucintamente como acontece a apropriação da obra por parte do leitor e como a entidade do autor é tratada e protegida por direitos autorais.

De acordo com Ivan Finotti e Juliana Calderari (2006, p. 103), as fanfics, ou fan fictions ou ainda ficções escritas por fãs, tratam-se de um tipo de texto em que o autor faz uso de elementos, personagens e situações de um universo já conhecido e, a partir disso, desenvolve suas próprias ideias. Essas narrativas podem ser ficcionais ou apenas tratar de descrições e especulações, teorias, sobre a obra original.

O site norte-americano Fanfiction (www.fanfiction.net) talvez seja o maior portal de publicação na internet deste tipo de texto, indexando em um único sítio as inúmeras revistas de fan fictions existentes - as fanzines - em domínios da internet - fandoms. Nesses domínios são incluídas histórias sobre filmes, seriados, jogos e livros - há pelo menos cinco finais alternativos para o livro Admirável Mundo Novo, de Aldous Huxley, e mais de 1.300 histórias relacionadas aos personagens de Os Miseráveis, de Victor Hugo.

Fanfic não é uma modalidade de escrita nova. Conforme Carmen Cardoso (apud FINOTTI; CALDERARI, 2006, p. 75), esse tipo de texto já existia na época de Guerra nas Estrelas. "Por exemplo, acaba um seriado e as pessoas começam a escrever em cima”, criando novos episódios, novas personagens ou teorias especulativas, mas sem deixar a ligação com a obra original.

Marianne MacDonald (2006, p. 28) afirma que as fanzines começaram a se difundir a partir da década de 1970, entretanto, com o advento da internet, o gênero subitamente ficou disponível para uma enorme gama de leitores que, além de lerem, produzem e publicam seus textos facilmente nos domínios. Segundo a mesma autora, a principal intenção dos fãs ao escreverem sobre suas obras favoritas não seria prestar uma homenagem aos escritores e seus textos, mas reinterpretar eventos ficcionais ao seu gosto. "For example, the relationships between characters are often altered or made more sexually explicit; the most popular theme of fan fiction is romance" ${ }^{4}$.

Mesmo colocando a “máquina preguiçosa” para funcionar, cumprindo a preciosa função de (re)significar o texto de literatura, de acordo
${ }^{2}$ Harry Potter e a Câmara Secreta (HP and the Chamber of Secrets), 1998; Harry Potter e o Prisioneiro de Azkaban (HP and the Prisoner of Azkaban), 1999; Harry Potter e o Cálice de Fogo (HP and the Goblet of Fire), 2000; Harry Potter e a Ordem da Fênix (HP and the Order of the Phoenix), 2003; Harry Potter e o Enigma do Príncipe (HP and the halfblood Prince), 2005; Harry Potter e as Relíquias da Morte (HP and the Deathly Hallows), 2007.

${ }^{3}$ Harry Potter series to be sold as e-books. BBC News - Entertainment \& Arts. 23 de junho de 2011.

4 "Por exemplo, com frequência as relações entre personagens são alteradas ou refeitas explicitando a sexualidade; $o$ tema mais popular de ficção escrita por fãs é o romance” (Tradução nossa). 
com a teoria de Eco (1994), esses leitores não poderiam ser chamados de 'modelo', já que não aceitam o limite ficcional, barreira imposta pelo autor-modelo, rebelando-se contra as instâncias reguladoras da narrativa.

A função dos contos 'imodificáveis' é precisamente esta: contra qualquer desejo de mudar o destino, eles nos fazem tocar com os dedos a impossibilidade de mudá-lo. E assim fazendo, qualquer que seja a história que estejam contando, contam também a nossa, e por isso nós o lemos e os amamos. (...) As histórias “já feitas” nos ensinam também a morrer. Creio que esta educação ao fado e à morte é uma das funções principais da literatura. (ECO, 2003, 21).

As fanfics demonstram a insubordinação do leitor empírico às leis estipuladas pelo autor-modelo para seu texto de ficção. Dumbledore morreu, por exemplo, e não há nada que possamos fazer para modificar este triste fato. Aceitar a morte inexorável do sábio mago é, neste caso, uma atitude necessária para os leitores de Harry Potter que desejam fazer o pacto ficcional com o texto como o autor-modelo idealizou. No entanto, as fan fictions mostram claramente que muitos leitores da série não querem simplesmente aceitar essa “educação ao fado e à morte” e acabam recriando acontecimentos a partir das ideias mais inusitadas.

Em entrevista ${ }^{5}$, a autora de Harry Potter admite que ama as teorias malucas e que sabia que após o lançamento do sétimo último livro da série, em 2007, os fãs iriam continuar a inventar teorias e histórias sobre as personagens. "Isso porque alguns estão interessados em personagens que não são centrais. Há, portanto, uma grande abertura para as fanfictions, assim como na obra de Jane Austin, de quem eu sou muito fã, mesmo após o término do livro você se pergunta sobre a vida das personagens" disse Rowling (FINOTTI; CALDERARI, 2006, p. 30).

Atualmente $^{6}$, liderando o ranking do Fanfiction.net, existem mais de 435 mil fanfics indexadas no site, um número exorbitante de teorias e pequenas histórias que se apropriaram das personagens, cenário, elementos e animais mágicos de todo o mundo de bruxaria que J. K. Rowling criou em Harry Potter. Contudo, toda essa "brincadeira” pode ter um custo. Embora Rowling tenha admitido que é adepta ao movimento de fanfics, moveu um processo contra uma editora na Rússia por ter publicado histórias de Harry Potter em sua versão feminina (FINOTTI; CALDERARI, 2006, p. 98). A autora também ganhou um processo contra a $R D R$ books, que quis publicar em papel o site The Harry Potter Lexicon (O Léxico de Harry Potter) organizado por um bibliotecário e fã da série, Steven Jan Vander Ark.

Enquanto o trabalho estava online e disponível gratuitamente a todos os internautas, Rowling elogiou o dicionário, assim como incentivava outros sites que se dedicavam ao universo Harry Potter. A autora até distribuía prêmios às melhores páginas da internet e em certa ocasião
${ }^{5}$ Entrevista aos sites norte-americanos The-leaky-cauldron e MuggleNet em 16 de julho de 2005.

${ }^{6}$ Última consulta em 14 de janeiro de 2015: <https://www. fanfiction.net/book/ Harry-Potter/> 
disse que usou do The Harry Potter Lexicon para pesquisas rápidas de termos dos seus próprios livros. Todavia, quando a editora $R D R$ anunciou a publicação do site em forma de livro, os advogados de Rowling entraram em ação alegando que a obra apenas seria uma compilação do trabalho de Joanne, ou seja, um plágio. A autora além de tudo criticou o trabalho de Ark, chamando o livro de preguiçoso e cheio de erros: "Não gosto da ideia de meus leitores gastando seu dinheiro com isso”, declarou?.

Porém, ela enfrentou um processo por plágio da obra Willy, o Bruxo, do escritor Adrian Jacobs, um autor de contos infantis que morreu em 1997. Max Markson, representante legal da herança de Jacobs, afirmou que Rowling plagiou ideias do livro de Adrian, já que ambos os escritores tiveram o mesmo agente literário, Christopher Little ${ }^{8}$.

Nesses episódios é possível perceber como acontece o processo de apropriação do texto ficcional e como autores recorrem a meios legais para defender seu “patrimônio”. Hoje, o mercado editorial é uma poderosa máquina do capitalismo, transformando o produto literário em mercadoria e propriedade.

Rowling, sem dúvida, é uma das mais bem pagas escritoras da história, mas ela começou bem de baixo. Recém divorciada e se recuperando da morte prematura da mãe, Joanne ficou muito feliz ao ter o livro aceito para publicação. Em entrevista a Sean Bullard da National Press Club - NPR Radio - em 20 de outubro de 1999, ela disse:

Quando eu terminei minha cópia do manuscrito, eu coloquei Joanne Rowling lá, esse sendo meu nome e tudo mais. E então meu editor britânico me ligou e, dois meses antes do livro ser publicado, disse: "Nós gostaríamos de usar suas iniciais” e eu disse, e para ser franca eu deixaria eles me chamarem Enid Snodgrass se eles publicassem o livro, então eu realmente não estava preocupara com isso. Minha gratidão era tão grande que então eu disse "ok, tudo bem, mas por quê?” e eles disseram... antes de tudo eles disseram "nós achamos que se destaca mais”, e eu disse "Por quê? Sério?”, e eles disseram "Nós achamos que meninos vão gostar desse livro, mas nós não temos certeza se eles vão escolhê-lo se eles pensarem que uma mulher o escreveu.” (...) E a coisa engraçada é que foi algo completamente desnecessário de se fazer, porque dois meses depois que o livro foi publicado eu estava na televisão em rede nacional, e eu não estava usando uma barba falsa ou nada.

Segundo Malone (2007, p. 178), a inicial K. veio da sua avó favorita, Kathleen. J. K. Rowling além de ocultar do nome a feminilidade, remete a uma conhecida tradição de abreviar o nome de escritores: J. R. R. Tolkien, C. S. Lewis, H. G. Wells, E. M. Forster, entre outros. A editora que sugeriu a abreviação do nome de Joanne temia o que Foucault previra há alguns anos: a punição, neste caso, vinda de um discurso machista que, durante muito tempo, imperou sobre o âmbito literário. No entanto, como o autor francês
${ }^{7}$ J.K. Rowling processa fã que quer escrever livro sobre Potter, diz NYT. Jornal Estadão online. 14 de abril de 2008.

${ }^{8}$ Matéria: Autora de 'Harry Potter' é processada por plágio. Terra. Arte e Cultura. 18 de fevereiro de 2010. 
também elucidou, “a ligação do nome próprio com o indivíduo nomeado e a ligação do nome do autor com o que nomeia, não são isomórficas e não funcionam da mesma maneira” (FOUCAULT, 1992, p. 43).

Assim, Rowling obteve muito sucesso mesmo o mundo sabendo que se tratava de uma mulher. A autora criou um império, uma vez que Harry Potter já foi traduzido para mais de sessenta línguas ${ }^{9}$ e se espalhou para todas as espécies de produtos comercializáveis, além de ter seu sucesso difundido pelos oitos filmes (o último livro foi dividido em duas partes) produzidos pela Warner Bros. Studios.

Ironicamente, mas de forma justificável, a escritora que não se importava em ser nomeada como homem, tendo sua identidade suprimida, desde que tivesse seu texto publicado, hoje lança processos contra aqueles que se apropriam da sua obra. As fan fictions nada mais são que uma apropriação muito particular do texto de J. K. Rowling, contudo, elas não devem assumir um status de obra sem pagar direitos autorais para a dona da marca Harry Potter.

Porém, há diversos livros que englobam o universo da série, mas todos trazem em sua capa, de forma muito explícita, uma mensagem do tipo "Este livro não é autorizado, aprovado, licenciado ou endossado por J. K. Rowling, Warner Bros. Entertainment Inc. ou qualquer pessoa associada com os livros e filmes da série Harry Potter" ${ }^{10}$, para que não haja nenhum problema com a autora ou com as entidades que compraram seus direitos autorais.

É claro que a série aqui considerada trata-se de um fenômeno de vendas, o chamado Best-seller, no entanto acredita-se que o tratamento não seria diferente considerando textos não tão famosos, já que hoje temos a produção literária não mais em regime de relações de patrocínio, mas sob a proteção de direitos autorais universais, os quais, contrariando Foucault e Eco, garantem e sustentam por leis que "o autor não está morto" e que mesmo após sua morte fisiológica tais leis manterão os direitos de propriedade do autor empírico sobre o texto.

\section{Referências}

Autora de 'Harry Potter' é processada por plágio. Terra. Arte e Cultura. 18 de fevereiro de 2010. Disponível em: $<$ http://diversao.terra.com.br/arte-ecultura/autora-de-39harry-potter39-e-processada-por-plagio,7858078553a 7a310VgnCLD200000bbceb0aRCRD.html>. Acesso em 28 set 2014.

Autora de "Harry Potter" não descarta possiblidade de novo livro. Folha de São Paulo. 07 de setembro de 2011. Disponível em: <http://www1. folha.uol.com.br/ilustrada/2011/07/940497-autora-de-harry-potter-naodescarta-possibilidade-de-novo-livro.shtml>. Acesso em 15 set 2014.

\begin{abstract}
${ }^{9}$ Autora de "Harry Potter" não descarta possiblidade de novo livro. Folha de São Paulo. 07 de setembro de 2011.
\end{abstract}

\footnotetext{
${ }^{10}$ Mensagem da capa do livro Harry Potter de A a $Z$ de Aubrey Malone (2007).
} 
BAKHTIN, M. O autor e a personagem. In: . Estética da Criação Verbal. Tradução de Paulo Bezerra. 4 ed. São Paulo: Martins Fontes, 2003, p. $3-20$.

BARTHES, R. A morte do Autor. In: O Rumor da Língua. Tradução Mário Laranjeira. São Paulo: Brasiliense, 1988, p. 66 - 71.

COMPAGNON, A. O autor. In: . O Demônio da Teoria: Literatura e Senso comum. 2 ed. Tradução de Cleonice Paes Barreto Mourão e Consuelo Fortes Santiago. Belo Horizonte: Ed. UFMG, 2001, p. 47 - 96

COMPAGNON, A. O leitor. In: . O Demônio da Teoria: Literatura e Senso comum. 2 ed. Tradução de Cleonice Paes Barreto Mourão e Consuelo Fortes Santiago. Belo Horizonte: Ed. UFMG, 2001, p. 139 - 164

ECO, U. Pós-escrito a O nome da Rosa. Rio de Janeiro: Nova Fronteira, 1985.

Seis passeios pelos bosques da ficção. Tradução de Hildegard Feist. São Paulo: Companhia das Letras, 1994.

- Sobre algumas funções da Literatura. In: Sobre a Literatura: Ensaios. 2 ed. Rio de Janeiro: Record, 2003, p. 09 - 21.

Entrevista de J. K. Rowling a Sean Bullard da National Press Club - NPR Radio. Potterish. 20 de outubro de 1999. Disponível em: <http://conteudo. potterish.com/transcricao-de-national-press-club-almoco-do-autor/>. Acesso em 10 set. 2014.

FINOTTI, I.; CALDERARI, J. O destino de Harry Potter. São Paulo: Conrad, 2006.

FOUCAULT, M. O que é um autor? 4 ed. Tradução de António Fernando Cascais e Edmundo Cordeiro. Portugal: Passagens, 1992.

HARMUCH, R. A.; OLIVEIRA. Literatura portuguesa I. Ponta Grossa: UEPG/ NUTEAD, 2010.

Harry Potter series to be sold as e-books. BBC News - Entertainment \& Arts. 23 de junho de 2011. Disponível em : <http://www.bbc.co.uk/news/ entertainment-arts-13889578>. Acesso em 10 set 2014.

J.K. Rowling processa fã que quer escrever livro sobre Potter, diz NYT. Jornal Estadão online. 14 de abril de 2008. Disponível em: <http://www. estadao.com.br/noticias/arteelazer,,156712,0.htm>. Acesso em 25 set. 2014.

MACDONALD, M. Harry Potter and the Fan Fiction Phenom. In: Gay \& Lesbian Review / Worldwide. Jan/Feb, 2006, Vol. 13. Issue 1, p. 2830. Disponível em: <http://connection.ebscohost.com/c/essays/19362052/ harry-potter-fan-fiction-phenom>. Acesso em 10 out. 2014. 
MALONE, A. Harry Potter de A a Z: o guia não-oficial definitivo de toda a série. Tradução de Daniel Queiroz de Souza Lima e Maria Inês Duque Estrada. Rio de Janeiro: Prestígio, 2007.

Enviado: 10/02/2015

Aprovado: 02/03/2015 